\title{
Hear What Employees Are Not Saying: A Review of Literature
}

\author{
Melissa Gonzales \\ Dreeben School of Education, University of the Incarnate Word, San Antonio, TX \\ Received: August 7, 2014 Accepted: August 22, 2014 Online Published: September 22, 2014 \\ doi:10.11114/jets.v2i4.520 \\ URL: http://dx.doi.org/10.11114/jets.v2i4.520
}

\begin{abstract}
A once organized, effective and, creative school teacher goes from "Teacher of the Year" candidate to an employee in need of improvement, without any notice of decline. The discouraged teacher begins to struggle with working relationships, schedules, and communication with students, parents, and colleagues. Why did the teacher never ask for help and how did the downfall go unnoticed? Added stressors, raised expectations and communication climate are variables worth noting as districts consider developing support systems and avenues of communication for teachers. The open door policy is convincing only if teachers feel safe and encouraged to discuss concerns, interests or suggestions. Organizations acknowledge communication issues cause problems, but the limited understanding about relationships and interactions between managers and employees remains (Lukaszewski, 2006).

This manuscript reviews research-based knowledge regarding employee/organizational communication. Particular attention is given to internal communications and existing support systems within school districts available to teachers. The topic is defined and internal organizational and campus communication is summarized. Benefits of open communication are considered, followed by a brief description of open communication theories, models and approaches. Roles of administrators, including barriers and ramifications of ineffective communication climates within organizations and campuses are discussed. The literature review concludes with views pertaining to measurements of communication performance initiatives.
\end{abstract}

Keywords: Open communications climate, organizational effectiveness, employee concerns, campus communication, teacher support systems.

\section{Introduction - Hear What Employees Are Not Saying: A Review of Literature}

A team working toward a common goal requires effective communication. When it comes to workplace communications, there is no shortage of theories and ideas of how to develop and implement internal communication strategies. The definition of a healthy communication climate describes the extent to which workers are motivated to meet organizational goals while being engaged with the philosophy and mission of the organization (Clampitt \& Downs, 1993.) A deprived organizational communication climate can lead employees to silence and withdrawal. Employees can become unhappy, stressed, and disaffected (Tamuz, 2001). Gaining insight into issues surrounding effective communication in resolving employee concerns can create discussion and development of policies and practices that directly influence and improve the school environment, employee relations, and school district success (Osborne-Lampkin, 2008).

Despite abundant research and the promotion of communications expertise as a product, organizations continue to struggle with successful internal communication with employees. As in most organizations, communication is an essential component of the teaching profession. Like most employees, teachers have the need to be heard. Internal communication among employees and administration on campuses impacts teacher engagement. Teacher's perception about how safe it is to be open and honest with administration is also impacted by communication culture on campus (Fagan-Smith, 2013). According to Leslie E. Laud, Principal (1998), instead of empowering teachers through mutual conversation, her impulse to direct and delegate bolstered administrator control and sustained a hierarchic campus culture. If leadership is not available to listen to employee concerns, frustrated employees may seek support from equally frustrated colleagues or representatives outside the organization.

\subsection{Importance of Open Communication}

Communication may be helpful in inspiring, building confidence, and creating the character of a group. It stimulates expression of concerns, emotions, and celebrates accomplishments. Communication is the foundation for employees 
and work groups as they build rapport with the organization and align themselves in the mission of the organization, in turn possibly creating a positive impact on retention. Preserving good employees is an essential workplace objective in most organizations. Concern with teacher retention has provoked diverse research. Inquiry related to variables that may influence teacher induction, engagement and retention have been considered (Koballa \& Bradbury, 2009).

According to the 2011 MetLife Survey of the American Teacher, teacher satisfaction has continually declined since 2008, making this the greatest decline in 25 years. The National Commission on Teaching and America's Future (NCTAF) released a report, Who Will Teach? Experience Matters (2010) finding that America's teacher attrition has doubled in the past fifteen years. The National Association of State Boards of Education (NASBE) recommends that school districts identify and address reasons why teachers leave the profession. School districts are faced with the challenge of retaining the most effective teachers in order for students to meet and exceed the standards being imposed.

A phenomenon that occurs in organizations is a common way of describing internal communications (Deetz, 2001). This perspective describes the organization as a capsule in which communication materializes. Internal communication can also be viewed as a way of describing an organization. Based on this viewpoint, communication is the fundamental mechanism through which employees develop working relationships, and get the essence of the culture and values of the institution. Communication is one of the most indicative activities in an organization (Harris \& Nelson, 2008). The operations and vitality of a system depends on capable and harmonious relationships among people and groups. In school systems, success of teams on campuses is achieved through profound social conversational processes (Jones, Watson, Gardner, \& Gallois, 2004).

\subsection{Communication Theories}

There are many theories, models and approaches to consider when assessing the phenomenon of employee/organization internal communication. Theoretical considerations to recognize include power distance and communication apprehension. Power distance refers to the extent of inequality among employees in different positions of authority. This inequality can be viewed as a natural or even desirable aspect of social order (Hofstede, 2001). Studies found that power distance moderates employee empowerment, a critical outcome of effective communications (Fock, Hui \& Bond, 2013). Communication apprehension (CA) refers to a level of real or anticipated panic or anxiety that a person experiences when communicating with another person (McCroskey, 1977). The theory of cognitive dissonance is about poor communication leading to incongruence. Festinger's (1957) cognitive dissonance theory supports that incongruence occurs when employees begin to experience conflict as disharmony occurs in a closed communication environment (Tompkins \& Cheney, 1985). Systems perspective is the foundation of the public relations excellence theory (Grunig, L., Grunig, J., \& Dozier, 2002). Excellence theory characterizes circumstances that promote or deter the creation of a culture for communication.

\subsection{Communication Models}

Communication models have evolved over time. The manner in which individuals communicate in the workplace today, could be a reflection of the model they were exposed to during their educational and professional development. Despite its current complexity, early models of internal communications focused on one-way communication. The Shannon-Weaver Model (1949) was a sender focused model and suggested that all meaning contained within a message would be understood if received. Berlo's (1960) model focused on relationships between the sender and receiver and suggested that the more highly developed the communication knowledge and skills of participants, the more effectively the message would be interpreted. Current models are more elaborate with the addition of media, high-speed and order of sharing immense communication (Burton, 2008). Formal communications planning is involved with current models and the focus is on the needs and concerns of the individual receiving the message. These differences in communication styles and approaches may infringe on trust and effective conversations.

\section{Communication Climate}

A healthy communication climate empowers employees and gives voice to what is important to them (Hirschman, 2008). Smidts, Pruyn and van Riel (2001), found effective internal communication helped employees in connecting with the identity of their organizations. The association of employees with an organization was more dependent on internal communication experiences rather than their perception of the organization's status or how established an organization was reported to be. Having employees perform at their best, while keeping them interested and engaged in their work is one of the most important concerns faced by organizations (D’Aprix, 2006).

\subsection{Communication Barriers}

A break-down of communication in an organization, can have a lasting impact on different employee groups and on objectives of each department. Communication researchers and practitioners defined and studied factors that inhibit open communications. Despite being invaluable, some behaviors hamper the interchange of communication and 
confuse the flow of information (Buchholz, 2001). Failing to listen or failure to keep others updated and informed can result in a closed communication climate, which may impact employee morale. Other feelings experienced by employees in a closed communication climate include lack of satisfaction, psychological stress, and job alienation (Ahghar, 2008).

\subsection{Teachers and Communication}

Whether they recognize it or not, teachers are the most important communicators in a district, based on the large amounts of information they give and receive on a daily basis. When engaged, teachers move from being docile employees to becoming progressive advocates (Woods \& Weasmer, 2004). To change teacher behaviors primarily through directing them disempowers them and does not allow the campus and district to profit from the their proficiency. The role of an open communication climate has been declared to be the most important element for successful school improvement ambitions (Halawah, 2005). Schools in which teachers have more input see less staff disharmony and less student misbehavior, thereby, creating a more positive climate. It is possible to restore hope over time, but if negative cultures exist for long periods, they become part of the school's reputation and are more difficult to change (Vail, 2005).

A contentious campus diminishes teacher mastery and their passion for teaching. An increase in morale may occur with the acknowledgement that everyone has a part in making the school successful (Osborne-Lampkin, 2008). Structures have to be in place allowing employees to share stressors or burdens before morale is impacted. Principals are also employees of the district and unhappy leaders hurt the morale of others (Vail, 2005).

Districts are continuously challenged with having to replace teachers who leave. While attempting to identify predictors that keep individuals in the educational profession researchers have found that strong ties between teacher and administrator are imperative to teacher commitment. Communication can improve employee efficacy and retention (Fugate, Prussia \& Kinicki, 2012). Employees who are engaged are more likely to feel positive about the organization, thereby minimizing turnover (Julia \& Rog, 2008). Teacher job satisfaction is definitely an indicator of teacher retention and commitment to the profession (Woods \& Weasmer, 2004). High turnover is costly, in terms of money and productivity. Teaching is challenging for educators, especially in their first three years of teaching, and those who reported poor communication relationships with administrators were less motivated to remain in the profession (Vail, 2005).

\section{Influence of Leadership on Communication}

Organizational leaders and campus administrators have a profound impact on organizational effectiveness. When leaders communicate and encourage communication they build rapport and as a result, employee loyalty expands, and employees connect with organizational goals and objectives. Research indicates that employees fear being retaliated against for raising concerns (Bednarz, 2012). One high school principal suggests that teachers should not fear retaliation for voicing concerns and should have confidence that administrators follow up on matters they bring up (Kessler \& Snodgrass, 2014).

The supervisory style of campus administration affects transparent communication and collaboration (Vakola \& Bouradas, 2005). The method in which administrators communicate with staff deserves attention, given that they spend much of their time conveying objectives and goals that must be met in order to maintain high levels of instruction and achievement. District transformational plans should address interaction among administrators and staff members. Halawah suggests that a component of administrator training should identify noted deficiencies and identify healthy practices to be utilized by principal's when addressing or resolving concerns of staff members, parents or community members (Halawah, 2005).

Forthright leaders make themselves available to hear input from others. At schools, administrators should be open to conversation with employees, parents, students, and anyone else interested in the management and well-being of a campus (Carr, 2007). When leadership is viewed as being supportive, it develops an environment where staff believes they can speak up and be heard. A school administrator focused on the superiority of the role and not willing to entertain new ideas is troublesome and will negatively influence both teachers and students (Bernstein, 1997). Glover stated that as a principal he listened for what he wanted and expected to hear rather than listening to individual concerns or fears presented by teachers. He found that this method ended dialogue, teachers stopped listening and no longer shared questions or ideas (Glover, 2007).

Eric Glover, a principal, describes three forms of conversations used in organizations: debate, dialogue, and open discussion. He notes that unfortunately, principal's primary form of conversation is debate. Literature not only recognizes that teachers want to be heard, but it also points out the rights and responsibilities they have to share concerns or objections with administration. Glover stated that expectations on his campus were that administration and 
staff worked together to create the best learning opportunities for every student, appreciated differences in perspectives and possibilities, engaged in team collaboration, and identified each person as having a moral responsibility to speak up for the benefit of students and the school. It was considered a professional obligation to point out inconsistencies or unreasonable ways of managing campus affairs (Glover, 2007).

\section{Measuring Communication}

Managing a process where employees are invited to voice concerns and receive timely feedback takes extensive planning. The cost associated with communication programs seem easier to measure than its benefits (Pandey \& Garnett, 2006). Although some assert that internal communication is a vital component of business achievement and conduct, few standards are imposed on what should be measured and how. One way of measuring communication performance is to use survey research methodologies (Gay, Mahoney \& Graves, 2005). Although subjective, this information may still add value (Dillman, 2000). Some guidance for auditing communication programs, developing surveys and measurement tools are shared by Sinickas (2005).

Confident protocols for measuring return on investment of professional communication programs have not been developed. Some of the items that organizations would like to measure are cost savings, surveys, focus groups, and outcome measures (Gay et al., 2005). Advancements in social media have created more questions for organizations. Organizations find themselves challenged in measuring the effects of new social media on internal and external communication effectiveness (Edelman, 2008). There is some progress in this area, but there is a need to develop improved ways of measuring the relationship among communication and future outcomes. It is suggested that improving communication performance will not be accomplished with the facilitation of one transformational initiative. Sustainable improvements will only be made over long term planning and execution of goals, targets, and interventions (Pandey \& Garnett, 2006).

\section{Discussion}

Employees in open communication climates are heard, supported and understood. When employees are involved in the decision making process they feel valued and begin to trust the communication channels and the information being shared with them. Individuals working in an open communication campus environment remain engaged while working hard to meet district goals. In school settings, healthy communication environments contribute to the overall success of the district, with positive impacts on employees, students, achievement and community collaboration.

Working in a closed communication environment is a universal phenomenon and it challenges resolution of employee concerns and the social dynamics of a campus and district. This particular issue can have a great impact on the success of teachers working under exceptional stressors and demands. If overwhelmed and frustrated teachers do not have a place they can turn to for support and guidance, they may experience defeat, lack in their ability to cope, thus causing other personnel issues for a district such as formal grievances, charges of discrimination, low performance, absences and high turn-over.

One of the most important findings came from the validation of the importance of the role of campus administrators. Teachers and administrators agreed on the importance of administration in promoting an open communication climate and campus culture. On school campuses, principals or assistant principal must be secure individuals, confident in their ability, while owning the position of authority as a campus administrator. A leader who communicates openly must be courageous and confident about operating with few or no communication barriers, even in the midst of tough conversations with employees.

The role of communication in organizational effectiveness - particularly employee empowerment is well studied, but education has much to gain from further assessing the role that communication plays on teacher satisfaction and retention. The benefits of campus communication culture efforts have not been analyzed in detail. There is also a lack of understanding and confidence in how to go about measuring communication performance. It would also be beneficial to study the effectiveness of the addition of social media to traditional communication systems.

The literature lacks detail pertaining to the connection between working in a closed communication school environment and the motivation of teachers to seek support and representation by unions or professional organization representatives. When teachers seek representation elsewhere the cost is great to the school district in terms of time, lack of productivity, legal fees, and employee splitting. The literature would benefit from further studies focused on the value teachers place on "being heard." There is absence of scholarly research conducted by human resource or employee relations professionals (Kennan \& Hazleton, 2006). These "communication professionals" may be viewed by employees as coordinators who simply execute directives imposed by upper management. A school district should try to determine why teachers seek support and advice from an attorney or union representative rather than turning to campus administrators, district officials or the human resource department for help and guidance. 
Reliable tests should be used to identify campuses and administrators in need of development. Campuses identified as disengaged communication climates should be equipped with formal communication systems customized to the needs and culture of that particular campus and community. Administrators established as lacking interpersonal communication and listening skills should complete district mandated training. Campus principals should also receive additional training regarding their role in initiating the transformational changes planned for their campus. Principals who score low on reliable tests should be connected with a mentor and monitored as they initiate strategies that allow employees to voice opinions, share concerns, and feel safe about speaking up and asking for help.

\section{Conclusion and Recommendations}

This literature review presents insights into the dynamics of open communication in the workplace. The teaching profession continues to challenge individuals that enter the public school classroom every day. Districts continue to strive to keep them excited about the teaching profession as they cope with increasing standards and expectations. Although there are many variables that attribute to an individual's desire to teach, the relevance of establishing a culture of open communication may prove to be advantageous in terms of organizational effectiveness, retention, and morale.

Effective communication is fundamental in every industry. As in most organizations, the importance of open communication in education cannot be overstated, but measuring the cost and benefits of communication initiatives remains a challenge. Gaining insight into the impact of communication on personnel issues could result in improved practices. Both administrators and teachers emphasized the importance of the role of leadership in creating a communication environment interested in 'hearing' what teachers have to say. Professional organizations, including school districts would benefit from taking a proactive approach to developing reputable, effective and confidential support systems for employees. Maybe if employees felt safe to communicate with leadership, their eagerness to consult with outside agencies and representatives would decline. This review of literature has identified gaps in the knowledge base regarding the effects of internal communication and support systems on the work environment, teacher well-being and retention. It is important to measure teacher perceptions and effectiveness of these systems in order to identify strengths and deficiencies to be considered by districts and school boards as they plan for transformation.

District administrators and school boards have important roles in attracting and retaining highly qualified teachers. School officials can negotiate with teacher professional organizations so that representatives share concerns and dissatisfactions they hear from teachers. A district could save time and money by addressing concerns early and quickly. District human resource departments should be proactive and solution focused, while offering necessary training to administrators. Making some of these changes could increase the chances of keeping successful and healthy teachers in the classrooms.

There is not enough known about internal campus communications and existing support systems available to attend to teacher concerns and the influence of these practices on teacher satisfaction, retention, performance and utilization of formal grievance processes. Examples for further research are listed below:

1. Qualitative studies may be conducted to gain in-depth information about existing internal campus communication and support systems available to teachers. The study should gain the perception of teachers regarding the effectiveness and credibility of existing practices and whether or not these perceptions influence the appeal of concerns to the formal grievance process.

2. Quantitative studies can be conducted to find the impact of communication and support systems on quality instruction and teacher performance in grades K-12.

3. These studies may be replicated at title one campuses of districts to gain better understanding of the types of support systems viewed as effective and credible, given the difference in dynamics of the title one school environment.

Internal communication and support systems are connected with segments of a positive place to work. When teachers are treated well, they will build healthy relationships with colleagues. When they perceive their environment as supportive, they teach at their best. In turn, the school becomes a pleasing and inviting place for talented individuals to work and students will have a great community in which to learn and develop (Johnson, S.M., Kardos, S.M., Kauffman, D., Liu, E., \& Donaldson, M.L., 2004).

\section{References}

Ahghar, G. (2008). The role of school organizational climate in occupational stress among secondary school teachers in Tehran. International Journal of Occupational Medicine and Environmental Health, 21, 319-329. http://search.ebscohost.com, http://dx.doi.org/10.2478/v10001-008-0018-8

Bednarz, T. (2012). Encourage questions to improve open communication. Contract Management, 52(11), 14-16.

Bernstein, C. (1997). A teacher's story of working in a non-supportive environment. Education, 118(1), 63-66. 
Berlo, D. (1960). The process of communication: An introduction to theory and practice. San Francisco: Rinehart Press.

Buchholz, W. (2001). Open Communication Climate. Bentley College Waltham, Massachusetts.

Burton, S.K. (2008, September 8). Personal communication.

Carr, N. (2007). Research and P.R. American School Board Journal, 194(8), 44-45.

Clampitt, P. \& Downs, C. (1993). Employee perceptions of the relationship between communication and productivity. Journal of Business Communications, 30(1), 5-28.

D’Aprix, R. (2006). Throwing rocks at the corporate rhinoceros: The challenges of employee engagement. In T.L. Gillis (Ed.), The IABC handbook of organizational communication (pp. 227-239). San Francisco: Jossey-Bass.

Deetz, S. (2001). Conceptual foundations. In F.M. Jablin \& L.L. Putnam (Eds.), The newhandbook of organizational communication: Advances in theory, research and methods (pp. 3-46). Thousand Oaks, CA: Sage Publications.

Dillman, Don A. 2000. Mail and Internet Surveys: The Tailored Design Method. $2^{\text {nd }}$ ed. New York: Wiley.

Edelman. (2008, June 26-27). North American New Media Academic Summit. [White Paper]. Chicago, IL: Edelman.

Fagan-Smith, B. \& Rosenblum, T. (2013). The value of trust. Communication World. Retrieved from http://cw.iabc.com/communicationworld/june_203?pg=22\#pg22

Festinger, L. (1957). A Theory of Cognitive Dissonance. Stanford, CA: Stanford University Press.

Fock, H., Hui, M., \& Bond, A. (2013). Moderation effects of power distance on the relationship between types of empowerment and employee satisfaction. Journal of Cross-Cultural Psychology 44(2), 281-298. http://dx.doi.org/10.1177/0022022112443415

Fugate, M., Prussia, G. E., \& Kinicki, A. J. (2012). Managing employee withdrawal during organizational change the role of threat appraisal. Journal of Management, 38(3), 890-914. http://dx.doi.org/10.1177/0149206309352881

Futernick, K. (2007) A possible dream: Retaining California teachers so all students learn. Sacramento, CA: California State University. Retrived July 31, 2014 from http://www.centerforpubliceducation.org

Gay, C., Mahoney, M., \& Graves, J. (2005). Best practices in employee communication: A study of global challenges and approaches. San Francisco: IABC Research Foundation.

Glover, E. (2007). Real principals listen. Educational Leadership, 65(1), 60-63.

Grunig, L., Grunig, J., \& Dozier, D.M. (2002). Excellent public relations and effective organizations: A study of communication management in three countries. Mahwah, NJ: Erlbaum.

Halawah, I. (2005). The relationship between effective communication of high school principal and school climate. Education, 126(2), 334-345.

Harris, T.E., \& Nelson, M.D. (2008). Applied organizational communication: Theory and practice in a global environment. New York: Lawrence Erlbaum.

Hirschman, C. (2008). Giving voice to employee concerns. HR Magazine, 53(8), 50-52.

Hofstede, G. (2001). Culture's consequences: Comparing values, behaviors, institutions, and organizations across nations. Thousand Oaks, CA: SAGE.

Johnson, S.M., Kardos, S.M., Kauffman, D., Liu, E. \& Donaldson, M.L. (2004, October 29). The support gap: New teachers' early experiences in high-income and low-income schools. Education Policy analysis Archives, 12(61). Retrieved July 31, 2014 from http://epaa.asu.edu/epaa/v12n61/.

Jones, E., Watson, B., Gardner, J., \& Gallois, C. (2004). Organizational communication: Challenges for the new century. Journal of Communication, 54(4), 722-750. http://dx.doi.org/10.1111/j.1460-2466.2004.tb02652.x

Julia, C. H., \& Rog, E. (2008). Talent management. International Journal of Contemporary Hospitality Management, 20(7), 743-757. http://dx.doi.org/10.1108/09596110810899086

Kennan, W.R., \& Hazleton, V. (2006). Internal public relations, social capital, and the role of effective organizational communication. In C.H. Botan \& V. Hazleton (Eds.), Public relations theory II (pp.311-340). Mahwah, NJ: Lawrence Erlbaum.

Kessler, S., \& Snodgrass, A. (2014). The house that affirmation builds. Educational Leadership, 71(5), 60-63.

Koballa, T., \& Bradbury, L. (2009). Mentoring in support of science teaching. In A. Collins \& N. Gillespie (Eds.),The continuum of secondary science teacher preparation: Knowledge questions and research recommendations (pp. 171-187). Boston: Sense Publications. 
Laud, Leslie E. (1998). Changing the way we communicate. Educational Leadership, 55(7), 23-25.

Lukaszewski, J. (2006). Rethinking employee communication: A strategic analysis, No. 5. Jim Lukaszewski Strategy.

Mayo, E. (1993). The human problems of an industrial civilization, Cambridge, MA: Harvard University Press.

McCroskey, J.C. (1977). Oral communication apprehension: A summary of recent theory and research. Human Communication Research, 4, 78-96.

MetLife Inc. (2011). Survey of the American Teacher: Teachers, Parents and the economy examines the views of teachers, parents and students about the teaching profession, parent and community engagement, and effects of the economy on teaching and learning in schools. Retrieved from: https://www.metlife.com/metlife-foundation/about/survey-american-teacher.html?WT.mc_id=vu1101

National Association of State Boards of Education (NASBE). (2012, March). Teacher Induction Improving State Systems for Supporting New Teachers. Retrieved from:

http://www.newteachercenter.org/sites/default/files/ntc/main/pdfs/brf_nasbe_discussion_guide_teacher_induction_ 0312.pdf

National Commission on Teaching and America's Future. (2010, January). Who Will Teach? Experience Matters. Retrieved from: http://nctaf.org/wp-content/uploads/2012/01/NCTAF-Who-Will-Teach-Experience-Matters-2010-Report.pdf

Osborne-Lampkin, L. (2008, March). Grievance arbitration in education. Paper presented at the American Educational Research Association, New York.

Pandey, S.K., \& Garnett, J.L. (2006). Exploring Public Sector Communication Performance: Testing a Model and Drawing Implications. Public Administration Review, 66(1), 37-51. http://dx.doi.org/10.1111/j.1540-6210.2006.00554.x

Shannon, C.E., \& Weaver, W. (1949). A mathematical theory of communication. Urbana: University of Illinois Press.

Sinickas, A.D. (2005). How to measure your communication programs: A practical manual for maximizing the effectiveness of your messages and media. ( $3^{\text {rd }}$ ed.). San Francisco: IABC Knowledge Centre.

Smidts, A., Pruyn, A.T.H., \& van Riel, C.B.M. (2001). The impact of employee communication and perceived external prestige on organizational identification. The Academy of Management Journal, 1-29.

Tamuz, M. (2001). Learning disabilities for regulators: the perils of organizational learning in the air transportation industry. Administration and Society, 33(3), 276-302.

Tompkins, P., \& Cheney, G. (1985). Communication and unobtrusive control in contemporary organizations. Organizational communication: Traditional themes and new directions, 13, 179-210.

Vail, K. (2005). Climate control: ten ways to make your schools great places to work and learn. American School Board Journal, 192(6), 16-19.

Vakola, M., \& Bouradas, D. (2005). Antecedents and consequences of organizational silence: an empirical investigation. Employee Relations, 274(4), 441-458. $\quad$ Retrieved from http://search.proquest.com/docview/235200611? accountid=7139

Woods, A. M., \& Weasmer, J. (2004). Maintaining job satisfaction engaging professionals as active participants. The Clearing House, 77(3), 118-121.

\section{(cc) EY}

This work is licensed under a Creative Commons Attribution 3.0 License. 